\title{
To manipulate or not to manipulate - A short comment on the game of interest rate manipulation
}

\author{
Andreas Haaker ${ }^{1,2}$ \\ ${ }^{1}$ Division of Fundamental Accounting Issues, DGRV - the German Cooperative and Raiffeisen Confederation Association, Berlin \\ ${ }^{2}$ Chair of Auditing, University of Hagen, Germany
}

Email adress:

andreas.haaker@fernuni-hagen.de (A. Haaker)

\section{To cite this article:}

Andreas Haaker. To Manipulate or Not to Manipulate - A Short Comment on the Game of Interest Rate Manipulation, International Journal of Economics, Finance and Management Sciences. Vol. 1, No. 1, 2013, pp. 21-24. doi: 10.11648/j.ijefm.20130101.13

\begin{abstract}
In this paper, bankster reputation as a coordination mechanism ("focal arbitrator") in the game of interest rate manipulation and the effects of punishment will be analyzed with the aid of game-theoretical instruments. In such a game with multiple equilibria, the "bad" to-manipulate equilibrium arises because of "bankster expectations". Under this condition, the game can, in the short term, only be changed through penalties so that the not-to-manipulate strategy becomes the dominant one. Should it happen that the bankster reputation be destroyed in the long term, penalties would, once again, become superfluous, because the "good" not-to-manipulate equilibrium would appear even in self-interested actions, due to the good banker expectations.
\end{abstract}

Keywords: LIBOR, Interest Rate Manipulation, Game Theory, Focal Point, Banksters

\section{Introduction}

The LIBOR (London Interbank Offered Rate) is one of the most important reference interest rates serving a number of valuation, transaction and contract purposes in the global financial system [1]. For a long time it was considered to be a suitable objective valuation standard. When it became public that this reference interest rate might have been manipulated systematically ([2], [3]), there was huge consternation [4]. The fact that the LIBOR is an interest rate which results from the average value of the refinancing costs of selected banks and that the reported data are estimated by those banks by themselves, has made the game of interest rate manipulation possible [5].

To manipulate the reference interest rate means here that a bank (or more precisely: a banker) knowingly reports another rate than the actual money market rate at which it may refinance on the interbank market. At least two variants of manipulation can be identified: manipulations in order to achieve speculative profits coordinately have happened on the one hand and manipulations to prevent a negative signal during the financial crisis on the other [4].

The interest rate manipulation mentioned first needs a coordinated approach and raises the following questions: Why is it that investment bankers can coordinate with each other and manipulate LIBOR to their advantage? What role does the image of "banksters" [6] play here? What do the politically stipulated penalties achieve?

Answering these questions would necessitate treating and analyzing problems of decision-making and coordination. The methodology of game theory is a useful tool in doing this, as it offers a formal-analytical language that helps such situations to be analyzed [7]. Professional players, such as investment bankers armed with market knowledge, are most likely to fulfill the game-theoretical prerequisites of rationality and being up-to-date (cf. [8], p. 2).

This essay applies simple game-theoretical models in order to ground its examination in game theory and not to offer a direct answer, which is only given outside the game matrix ([9], p. 33). These models serve to structure the examination and provide a basis for analysis but must not be more precise and more exact than the problem at hand demands ([10], p. 22). Therewith, it will also be shown how a well-understood application of game theory can contribute to the analysis of politically relevant economic questions, without wishing to fulfill the excessive demands involved in reproducing reality directly [11]. 


\section{Bankster Reputation as a "Focal Ar- bitrator" in the Game of Interest Rate Manipulation}

The following analysis can be simplified by assuming only two players (Bankster 1 and Bankster 2) with an equal portfolio of financial instruments. Each has the possibility of manipulating or not ("to manipulate or not to manipulate"). This means, for example, if both players bet with an identical swap on an increasing LIBOR, they will have the option to report either an excessive interest rate or to report the "true" one. Table 1 illustrates this game situation (for mathematical derivation of the modelling date see [12]).

Table 1. Interest rate manipulation game with multiple equilibria.

\begin{tabular}{llllll}
\hline & & \multicolumn{3}{l}{ Bankster 2 } & \\
\cline { 3 - 5 } & & $\begin{array}{l}\text { not to } \\
\text { manipulate }\end{array}$ & to manipulate \\
Bankster 1 & $\begin{array}{l}\text { not to } \\
\text { manipulate } \\
\text { to manipulate }\end{array}$ & $\mathrm{a}^{*}$ & $\mathrm{a}^{*}$ & & $\mathrm{~b}$ \\
& $\mathrm{~b}$ & $\mathrm{c}$ & $\mathrm{c}$ & $\mathrm{d}$ \\
\hline
\end{tabular}

The game matrix depicts the payoffs dependent upon the manipulative behavior of both "banksters" [6]. The banksters payoffs depend not only on their own particular manipulative behavior, but also on that of the other player. Each field denotes a possible manipulative strategy combination of both banksters (not to manipulate/not to manipulate, not to manipulate/to manipulate, to manipulate/not to manipulate, and to manipulate/to manipulate) with the respective payoff for bankster 1 given on the bottom left (southwest) and for bankster 2 on the top right (northeast). If bankster 1 were, for example, to manipulate the interest rate but bankster 2 were not, bankster 1 would receive a payoff from $b$, while bankster 2 would receive a payoff from c (see table 1).

The following payoff relation is assumed: $d>c>a>b$, so that there are two possible pure strategy Nash equilibria (a two-sided to-manipulate or a two-sided not-to-manipulate). How is this situation explicable from an economic viewpoint? As long as both manipulate, both can maximize their trading gains and the associated bonuses in a relatively untrammeled manner [13]. Consequently, a two-sided to-manipulate is more advantageous to all players than a two-sided not-to-manipulate $(d>a)$. $d$ represents the maximum profit in the case of manipulation on both sides, while without coordinated manipulation only a profit of " $\mathrm{a}$ " is realised. The difference between $\mathrm{d}$ and $\mathrm{a}$ is the advantage of the double-sided manipulation where both players report simultaneously a higher or lower interest rate [12].

If a player does not manipulate the interest rate but the other one does, the honest one suffers the net interest income losses accordingly; thus $\mathrm{c}<\mathrm{d}$ is valid. If the interest rate is manipulated by only one player, the danger that the manipulator's cover will be blown is great, which is why the disadvantages outweigh the higher trading gains and bonuses to the extent that a one-sided manipulation is not worth it; thus $\mathrm{a}>\mathrm{b}$ is valid. (If this condition were not fulfilled, to-manipulate would constitute the dominant strategy, making manipulation always sensible, which is not presumed here.).

Two pure strategy Nash equilibria, therefore, exist, in which no player can improve through a change of strategy. (A situation in which the players play with a mixed Nash equilibrium strategy, thereby allowing a random generator to decide whether to manipulate, should realistically not be taken into account.) Whichever of the two pure strategy Nash equilibria is reached is initially open, with the two-sided (utility-maximizing) to-manipulate strategy being pareto efficient for both parties (nobody can improve without leaving the other one worse off).

When the other player does not manipulate, it is advantageous to also not manipulate (pay-off: a instead of $b$ ). Likewise, if he does manipulate, following the same to-manipulate strategy ( $\mathrm{d}$ instead of $\mathrm{c}$ ) is optimal. For the rest of the financial system, whose participants have to bear the external costs of the game [14], $\mathrm{a}^{*} / \mathrm{a}^{*}$ (a two-sided not-to-manipulate) would certainly be the better Nash equilibrium, but for the two "banksters" it is instead $\mathrm{d}^{* *} / \mathrm{d}^{* *}$ (a two-sided to-manipulate).

Mathematics does not offer a solution as to which of the two equilibria will arise in the case of pure strategy multiple equilibria (cf. [8], $113 \mathrm{f}$.). "The answer is not in the matrix. The question is nicely formulated in the matrix, the answer is not" ([9], p. 33). According to Schelling's focal-point effect ([15], 57), though, a distinctive equilibrium will develop, because in this case an indication that the other person is employing one of these equilibrium strategies, which he only does when he suspects that the other is doing the same, would suffice (cf. [16], p. 1111). The focal- point solution must simply be salient ([17], p. 225).

As $\mathrm{d}^{* *} / \mathrm{d}^{* *}$ (a two-sided to-manipulate) is pareto efficient, (unspoken yet unambiguous) agreements to play using the to-manipulate strategy would always be credible (cf. [9], p. 37), because there is no reason for either player to deviate (= Nash equilibrium). Playing with the payoff-maximizing strategy, therefore, becomes more probable especially with repeated games and adaptive players (Payoff Dominance: [18], pp. 80 ff.).

The bankster reputation, which can prove to be the "focal arbitrator" ([8], p. 111) by coordinating the strategy expectations of playing the manipulation strategy at the cost of others, is the final missing element of the self-fulfillment of these expectations (focal point) regarding the occurrence of the "manipulation equilibrium". The playing of a mixed strategy Nash equilibrium would hardly be sensible here due to the two-sided advantageousness of the pure manipulation strategy (cf. [18], pp. 80 f.; [19], p. 62).

As long as the players, too, deem the image of the bankster accurate, the to-manipulate equilibrium will probably be played. The self-fulfilling expectations of the banksters ought, therefore, to be changed in the direction of the not-to-manipulate equilibrium, by instilling the belief that the other player is an honest banker. In doing so, the game 
remains unchanged because "it is only part of a larger game. There is always a larger game" ([20], p. 28). "If you don't like the game you are playing, look for the larger game" ([20], p. 334). Whichever economic equilibrium occurs is, thus, a question of morality and values. Appeals to morality and public critique of "glaring moral deficits" [21] are, therefore, economically well founded.

\section{Using Punishment to Change the Game(s)}

In order to change the game on a short-term basis, in light of publicly stated "moral deficits" and, thus, to simultaneously change the expectations regarding manipulative behavior in the long term (in which case the changes to the game would be superfluous), deterring penalties could, of course, be imposed [21]. Fines and imprisonment must be stiff enough to sufficiently discourage a one-sided to-manipulate. This is not the case when $\mathrm{d}>\mathrm{c}$ is assumed. Thus a penalty $(\mathrm{t})$ would have to be imposed, which, considering the probability ( $\mathrm{pm}$ ) of being caught in a two-sided to-manipulate, would lead to $\left(\mathrm{d}-\mathrm{t}^{*} \mathrm{pm}\right)<\mathrm{c}(\mathrm{cf}$. Table 2$)$. The positive probability $\mathrm{pm}$ is, moreover, a lever for financial supervision. pnm, here, is the positive probability of being caught in a one-sided to-manipulate. As $a>b, a>\left(b-t^{*}\right.$ pnm). Also valid is $\mathrm{c}>\mathrm{d}-\mathrm{t}^{*} \mathrm{pm}$, which is why a not-to-manipulate strategy is the dominant one for both banksters, consequently ensuring that a desired equilibrium (not-to-manipulate/not-to-manipulate) will be chosen by the players out of self-interest. This changes the long-term expectations, rendering the penalty superfluous, because with the discontinuation of the bankster reputation the "good" not-to-manipulate equilibrium would be played instead of the "bad" to-manipulate equilibrium once again.

Table 2. Interest rate manipulation game with penalty.

\begin{tabular}{rlllll}
\hline & \multicolumn{3}{l}{ Bankster 2 } & \\
\cline { 3 - 6 } & $\begin{array}{l}\text { not to } \\
\text { manipulate }\end{array}$ & \multicolumn{2}{c}{ to manipulate } \\
\hline Bankster 1 & $\begin{array}{l}\text { not to } \\
\text { manipulate } \\
\text { to manipulate }\end{array}$ & $\mathrm{a}^{*}$ & $\mathrm{a}^{*}$ & $\mathrm{c}$ & $\mathrm{b}-\mathrm{t}^{*} \mathrm{p}_{\mathrm{nm}}$ \\
& $\mathrm{b}-\mathrm{t}^{*} \mathrm{p}_{\mathrm{nm}}$ & $\mathrm{c}$ & $\mathrm{c}$ & $\mathrm{d}-\mathrm{t}^{*} \mathrm{p}_{\mathrm{m}}$ \\
\hline
\end{tabular}

\section{Conclusion}

To manipulate the reference interest rate means that a bank knowingly reports another rate than the actual money market rate at which it may refinance on the interbank market. With coordinated manipulation (i.e. reporting of false interest rates) one can realise higher speculation profits. In such a game of interest rate manipulation with multiple equilibria, the "bad" to-manipulate equilibrium arises because of "bankster expectations". Under this condition, the game can, in the short term, only be changed through penalties so that the not-to-manipulate/not-to-manipulate strategy becomes the dominant one. Should it happen that the bankster reputation be destroyed in the long term, penalties would, once again, become superfluous, because the "good" not-to-manipulate equilibrium would appear even in self-interested actions (cf. [22], p. 583), due to the "good banker expectations" - "from ought to to want to" ([23], p. 253).

Some commentators believe in accordance with chapter 3 that at the end of the day only tougher penalties will help [24]. The conclusion that penalties can influence behavior positively appears banal. This does not apply to the assumption that the "game situation" without penalties allows "good" behavior for rational players as an equilibrium of the game of interest rate manipulation. This shows clearly that the solution to the problem cannot (only) be the change of the reporting procedures of interest rates, but rather a question of "culture" in finance industry. Identifying the necessary measures [25] for this goes beyond the content of the previous analysis applying game theory.

\section{References}

[1] Snider, Connan and Thomas Youle (2009), Diagnosing the LIBOR: Strategic Manipulation and Member Portfolio Positions, Working Paper (unpublished).

[2] Abrantes-Metz, Rosa M. et al. (2009), „Libor manipulation?“, Journal of Banking \& Finance 36 (1), 136-150.

[3] Ellis, David M. (2011), LIBOR Manipulation: A Brief Overview of the Debate, FTI UK London.

[4] Siedenbiedel, Christian (2013), "Die Libor-Bande", Frankfurter Allgemeine Sonntagszeitung, No. 21, 21-22.

[5] Maisch, Michael (2013), "Der Libor ist ein Auslaufmodell", Handelsblatt, No. 10, 26.

[6] Economist (2012), "Banksters", The Economist 404 (8792), 14.

[7] Holler, Manfred J. and Gerhard Illing (2006), Einführung in die Spieltheorie, 6th ed., Springer, Berlin et al.

[8] Myerson, Roger B. (1992), Game Theory: Analysis of Conflict, Harvard University Press, Cambridge and London.

[9] Schelling, Thomas C. (2010), "Game Theory: A Practitioner's Approach", Economics and Philosophy 26 (1), 27-46.

[10] Popper, Karl R. (2006), "Wie ich die Philosophie sehe”, in: Popper, K. R., Alle Menschen sind Philosophen, 6th ed., Piper Verlag, München, 11-22.

[11] Rubinstein, Ariel (1991), "Comments on the Interpretation of Game Theory”, Econometrica 59 (4), 909-924.

[12] Haaker, Andreas (2012), Zur Manipulation von Referenzzinssätzen: Versuch einer einfachen spieltheoretischen Analyse des Grundproblems, Working Paper, Berlin (unpublished).

[13] Böll, Sven et al. (2012), "Das Kartell”, Der Spiegel, No. 31, 64-70.

[14] Coase, Ronald H. (1960), "The Problem of Social Cost", 
Journal of Law and Economics 3 (Oct.), 1-44.

[15] Schelling, Thomas C. (1960 [1980]), The Strategy of Conflict, Harvard University Press, Cambridge and London.

[16] Myerson, Roger B. (2009), "Learning from Schelling's Strategy of Conflict", Journal of Economic Literature 47 (4), 1109-1125.

[17] Kirchgässner, Gebhard (2008), Homo Oeconomicus, 3rd ed., Mohr Siebeck, Tübingen.

[18] Harsanyi, John C. and Reinhard Selten (1988 [1992]), A General Theory of Equilibrium Selection in Games, The MIT Press, Cambridge and London.

[19] Binmore, Ken (2007), Game Theory, Oxford University Press, New York.
[20] Dixit, Avinash K. and Barry J. Nalebuff, (2010), The Art of Strategy, W. W. Norton \& Company, New York and London.

[21] Ludwig, Thomas (2012), "EU zeigt keine Toleranz für Zinsmanipulationen”, Handelsblatt, No. 143, 27.

[22] Hurwicz, Leonid (2008), "But Who Will Guard the Guardians?", American Economic Review 98 (3), 577-585.

[23] Arnold, Volker (2009), "Vom Sollen zum Wollen - über neuere Entwicklungen in der Wirtschaftsordnung", Perspektiven der Wirtschaftspolitik 10 (3), 253-265.

[24] Maisch, Michael (2013), "Blick zurück im Zorn", Handelsblatt, No. 30, 27.

[25] The Wheatley Review (2012), The Wheatley Review of LIBOR: final report, September 2012. 